\title{
Savory's Unsubstantiated Claims Should Not Be Confused With Multipaddock Grazing
}

\author{
By David D. Briske, Brandon T. Bestelmeyer, and Joel R. Brown
}

The sole objective of our critique of Mr Savory's TED video published in Rangelands ${ }^{1}$ was to "fact check" a portion of the extraordinary claims that he had made relative to sciencebased information. It is incumbent upon a professional discipline to evaluate the relevant evidence and potential viability of proposed management strategies and policies. Regrettably, Richard Teague's response does not address any of $\mathrm{Mr}$ Savory's claims that we addressed in our critique- not all global rangelands are degraded, rangelands have a limited capacity to store carbon, and intensive rotational grazing is not necessary to prevent rangelands from degrading. Here we reiterate these last two points of our initial critique, then address the concerns presented by Teague, and conclude with comments regarding the future direction of grazing systems research.

\section{Justification of Savory TED Video Critique}

Global rangelands (including grasslands) are frequently characterized by low and highly variable productivity, which minimizes the potential for large and rapid responses to management actions. Mr Savory's oversimplification of rangeland function and denouncement of science in order to promote extravagant claims regarding his grazing methodreversal of climate change and desertification-potentially weaken the credibility and position of the rangeland profession relative to other scientific disciplines and with policymaking groups. Furthermore, Mr Savory's claim “that science has never discovered anything" serves to isolate science and management at a time when stronger partnerships are needed among management, science, and policy makers to produce information that has greater management and policy effectiveness. ${ }^{2,3}$

No attempt was made by Teague to address the lack of evidence regarding Mr Savory's claim that his grazing method can sequester vast amount of carbon dioxide from atmosphere into soils to reduce climate change. The biophysical limits on the capacity of rangelands to sequester carbon are well understood and are primarily established by low and variable precipitation. ${ }^{4}$ Consequently, management strate- gies first and foremost emphasize conservation of existing soil carbon by mitigating actions that may contribute to its loss, rather than attempting to maximize sequestration of additional atmospheric carbon. ${ }^{5,6}$ Misrepresentation of the potential for grazing management to sequester vast amounts of atmospheric carbon in rangeland soils diverts attention from the more viable strategy of adaptation planning to minimize the risk of climate change on human livelihoods derived from livestock grazing. ${ }^{6}$ Adaptation planning is where holistic management and adaptive grazing management can make their greatest contribution to human livelihoods in response to climate change.

Further, Teague's response makes no mention of $\mathrm{Mr}$ Savory's claims that "periodic trampling [by livestock] is necessary to prevent degradation" by minimizing biological crusts that increase runoff and evaporation. Here again, there is no conclusive evidence to support the generality of these claims, and there are several important reasons why disturbing the soil surface is undesirable in many rangelands. The concern regarding excessive soil erosion has been expressed by one of Mr Savory's supporters, Mr Goodloe. ${ }^{7}$ The purported benefits of surface soil disturbance would have to be sufficient to offset the negative consequences of soil exposure to wind and water erosion, and an accelerated release of soil carbon and a reduction of nitrogen fixing capacity associated with damage to soil crusts. ${ }^{8,9}$ We acknowledge that there may be cases where trampling of previous years' plant material on the soils surface may be valuable, but it is difficult to envision how it represents a central feature of all grazing management. Excessive accumulation of dead plant material is certainly not the most pressing problem confronting grazing management, especially in arid and semiarid regions.

Here we reemphasize that the claims made by Mr Savory in the TED video are unsubstantiated and represent an unfortunate distraction from legitimate and proven procedures, processes, and outcomes of grazing management. Consider Mr Savory's claims in relation to information presented in the Rangelands special feature focused on grazing management 
(2013, 35:72-74), which provides an excellent overview of contemporary approaches to rangeland grazing management. The emphasis on "complex creative (adaptive) systems" characterized by ever changing relationships among organisms and the environment represents the backdrop against which all of rangeland management is conducted. ${ }^{3}$ The necessity of adaptive management-systematic learning and adjustments based on successes and failures of previous managementwas effectively described by Ortega-S and coauthors ${ }^{10}$ and directed toward rangeland restoration by Steffens and coauthors. ${ }^{11}$ These are the flexible, learning-oriented approaches to rangeland grazing management that should be promoted, rather than the narrow, singular prescription advocated in the Savory TED video.

\section{Response to Teague Comments}

The criticisms presented by Teague of our previously published statements regarding grazing systems reflect a major misunderstanding of our original position. We have never claimed that rotational grazing was unsuccessful because the experimental grazing research does not support this conclusion. The major point of contention regarding rotational grazing was that many of the claims of ecological benefits were unsubstantiated by credible evidence, which have now been elevated even further by the Savory TED video. Similarly, we have never advocated for use of continuous grazing over any other grazing systems. Continuous grazing is referenced in our prior assessments because it is a commonly used reference for experimental comparison with other grazing systems. Our consistent position has been as stated in Briske and colleagues ${ }^{12}$ :

experimental data demonstrate that a set of potentially effective grazing strategies exist, none of which have unique properties that set one part from the other in terms of ecological effectiveness. The performance of all grazed ecosystems is constrained by similar categories of ecological variables indicating that differences among them are dependent on the effectiveness of management models, rather than unique ecological phenomena ... This evidence [experimental grazing research] supports rotational grazing as a viable grazing strategy on rangelands. (p. 11)

Furthermore, we agree that the grazing management principles outlined in Teague and others ${ }^{13}$ - providing for postgrazing plant recovery and managing livestock distribution, grazing intensity, and foraging behavior are fundamental to rangeland management - and they are by no means unique to multipaddock grazing. These principles were developed and promoted prior to introduction of the Savory method, ${ }^{14}$ and they were devised with scientific methodology that $\mathrm{Mr}$ Savory has denounced.

The claims that Mr Savory stated in the TED video are even unsupported by the data of Teague and colleagues ${ }^{15}$ that is frequently referenced by Savory advocates. These data in- dicate that 1) soils under multipaddock rotation had similar soil carbon stocks, runoff rates, sediment loss rates, and infiltration rates compared to ungrazed rangeland and 2) the amount of bare ground and peak standing crop biomass were not statistically distinguishable between multipaddock rotation and ungrazed rangeland. These comparative responses indicate that long-term ungrazed rangeland was not degrading, was not impaired with regard to infiltration and runoff, and stored the same amounts of carbon as rangelands that were managed with what is presumably the Savory method. $\mathrm{Mr}$ Savory's claims that "periodic trampling is necessary to prevent degradation" and that "soil organic carbon can be greatly increased" by his grazing method compared to ungrazed rangelands are inconsequential to multipaddock grazing, and there is no valid reason to use them as a reference of potential benefits. This comparative study does indicate, however, that an effectively managed four-paddock one-herd rotation system produced greater ecological benefits compared to heavy continuous grazing in terms of slightly higher soil carbon stocks, similar runoff rates, lower bare ground and sediment loss, and higher standing crop biomass. However, we wish to caution that these data were obtained from three individual ranches, each operating with a distinct grazing systems and presumably varying intensities of adaptive management, and in a mesic rangeland ( 32 inches rainfall annually) that is likely to be quite different in its responses compared to arid and semiarid rangelands.

Teague endorses sound hypothesis testing by "seeking information that refutes any hypothesis," yet he then recommends that "results from small scale grazing research should largely be set aside as being of little relevance to any discussion of grazing distribution on commercial ranches." We maintain that scientific inquiry requires development of a framework or theory that accommodates all relevant information, including both experimental and management sources in the case of grazing management. ${ }^{16}$ Teague and colleagues $^{13}$ have developed a valuable assessment of the potential deficiencies of the data produced by experimental grazing research, but the majority of these concerns had previously been addressed in our earlier assessments. ${ }^{12,16} \mathrm{We}$ respectfully suggest that our acknowledgement of these deficiencies and attempts to use all documented evidence refutes any misrepresentation of the experimental data on our behalf as claimed by Teague.

To the extent that the collective evidence regarding grazing systems has been evaluated, including the research of Teague and colleagues, effective adaptive management appears to be a central component of successful outcomes. ${ }^{15,17,18}$ More research utilizing the comparative approach among ranch enterprises as applied by Jacobo and others ${ }^{19}$ and Teague and colleagues ${ }^{15}$ will help to identify the potential outcomes originating from the interaction among adaptive management and grazing system. However, this comparative approach is unlikely to identify a "superior" grazing system because the benefits of a grazing system are not easily sepa- 
rated from the contribution of effective management. On one hand, this is a seemingly trivial point because ecologically and economically sustainable enterprise management is the primary goal, but on the other hand, disentangling the relative contributions of adaptive management and grazing system will greatly increase understanding of adaptive management and identify indicators and decision-making processes that managers rely on for timely and effective decisions. Insights into the interaction among adaptive management and grazing systems would greatly support effective transfer of these management skills and guide research to identify the most important aspects of adaptive management.

\section{Reflections on Future Research}

Teague and colleagues ${ }^{13}$ offer several viable hypotheses and approaches for advancing our understanding of rangeland grazing management. Their underlying assumption is that "multi-paddock grazing, when managed to give best vegetation and animal performance, has the potential to provide superior conservation and restoration outcomes" ( $\mathrm{p}$. 712). However, this assumption is largely dependent upon the motivation and capabilities of managers to identify and produce the best outcomes. We contend that this is the fundamental issue in promoting desirable outcomes for all grazing enterprises, and this is why we consider the Rangeland special feature on grazing management to be a significant contribution. This points to what may be the central questions remaining in the grazing systems debate: How can adaptive management be more effectively implemented and incentivized for managers with diverse motivations and capabilities? Does adaptive management contribute to effective grazing systems, or does it originate from them? A renewed focus on adaptive grazing management, as represented in the Rangelands special feature, should replace the search for a single, superior grazing system that is effective on global rangelands. Mr Savory's claims as stated in the TED video should not be confused with multipaddock grazing, and they should not be used to guide any aspect of grazing management or research.

\section{References}

1. Briske, D. D., B.T. Bestelmeyer, J. R. Brown, S. D. Fuhlendorf, and H. W. Polley. 2013. The Savory method can not green deserts and reverse climate change. Rangelands 35:72-74.

2. BRiske, D. D. [ED.]. 2011. Conservation benefits of rangeland practices: assessment, recommendations, and knowledge gaps. Lawrence, KS, USA: Allen Press. 429 p.

3. Provenza, F., H. Pringle, D. Revell, N. Bray, C. Hines, R. Teague, T. Steffens, and M. Barnes. 2013. Complex creative systems: principles, processes and practices of transformation. Rangelands 35:6-13.

4. Svejcar, T., R. Angell, J. A. Bradford, W. Dugas, W. Emmerich, A. B. Frank, T. Gilmanov, M. Haferkamp, D. A. Johnson, H. Mayeux, P. Mielnick, J. Morgan, N. Z. Saliendra, G. E. Schuman, P. L. Sims, and K. Snyder. 2008. Car- bon fluxes on North American rangelands. Rangeland Ecology \& Management 61:465-474.

5. Booker, K., L. Huntsinger, J. W. Bartolome, N. F. Sayre, and W. Stewart. 2013. What can ecological science tell us about opportunities for carbon sequestration on arid rangelands in the United States? Global Environmental Change 23:240-251.

6. Joyce, L. A., D. D. Briske, J. R. Brown, H. W. Polley, B. McCarl, and D. W. Bailey. 2013. Climate change and North American rangelands: assessment of mitigation and adaptation strategies. Rangeland Ecology \& Management 66:512-528.

7. Goodloe, S. 2013. Short-duration grazing in retrospect-a practitioner's experience. Rangelands 35:67-71.

8. Barger, N. N., J. E. Herrick, J. Van Zee, and J. Belnap. 2006. Impacts of biological soil crust disturbance and composition on $\mathrm{C}$ and N loss from water erosion. Biogeochemistry 77:247-263.

9. Thomas, A. D. 2012. Impact of grazing intensity on seasonal variations in soil organic carbon and soil $\mathrm{CO}_{2}$ efflux in two semiarid grasslands in southern Botswana. Philosophical Transactions of the Royal Society B 367:3076-3086.

10. Ortega-S, A. J., S. D. Lukefahr, and F. C. Bryant. 2013. Optimum stocking rate, monitoring, and flexibility: key components of successful grazing management programs. Rangelands 35:22-27.

11. Steffens, T., G. Grissom, M. Barnes, F. Provenza, and R. RoAth. 2013. Adaptive grazing management for recovery. Rangelands 35:28-34.

12. Briske, D. D., J. D. Derner, J. R. Brown, S. D. Fuhlendorf, W. R. Teague, K. M. Havstad, R. L. Gillen, A. J. Ash, and W. D. Willms. 2008. Rotational grazing on rangelands: reconciliation of perception and experimental evidence. Rangeland Ecology Eं Management 61:3-17.

13. Teague, R., F. Provenza, U. Kreuter, T. Steffens, and M. BARnes. 2013. Multi-paddock grazing on rangelands: why the perceptual dichotomy between research results and rancher experience? Journal of Environmental Management 128:699-717.

14. Stoddart, L. A., A. D. Smith, and T. W. Box. 1975. Range management. New York, NY, USA: McGraw-Hill. 532 p.

15. Teague, W. R., S. L. Dowhower, S. A. Baker, N. Haile, P. B. DeLaune, and D. M. Conover. 2011. Grazing management impacts on vegetation, soil biota and soil chemical, physical and hydrological properties in tallgrass prairie. Agriculture, Ecosystems E Environment 141:310-322.

16. Briske, D. D., N. F. Sayre, L. Huntsinger, M. FernandezGimenez, B. Budd, and J. D. Derner. 2011. Origin, persistence, and resolution of the rotational grazing debate: integrating human dimensions into rangeland research. Rangeland Ecology \& Management 64:325-334.

17. Pinchak, W. E., W. R. Teague, R. J. Ansley, J. A. Waggoner, AND S. L. Dowhower. 2010. Integrated grazing and prescribed fire restoration strategies in a mesquite savanna: III. Ranchscale cow-calf production responses. Rangeland Ecology Eं Management 63:298-307.

18. Teague, W. R., S. L. Dowhower, R. J. Ansley, W. E. Pinchak, And J. A. Waggoner. 2010. Integrated grazing and 
prescribed fire restoration strategies in a mesquite savanna: I. Vegetation responses. Rangeland Ecology E Management 63:275-285.

19. Jacobo, E. J., A. M. Rodríguez, N. Bartoloni, and V. A. Deregibus. 2006. Rotational grazing effects on rangeland vegetation at a farm scale. Rangeland Ecology \& Management 59:249-257.
Authors are Professor, Dept of Ecosystem Science and Management, Texas AE'M University, College Station, TX 77843, USA, dbriske@tamu.edu (Briske); Research Ecologist, USDA-ARS, Jornada Experimental Range and Jornada Basin LTER, New Mexico State University, Las Cruces, NM 88003, USA (Bestelmeyer); and Research Scientist, USDA-NRCS, Jornada Experimental Range, Las Cruces, NM 88003, USA (Brown). 